\title{
Age does not influence the disease course in a mouse model of Streptococcus pneumoniae serotype 3 meningitis
}

\author{
Anja Manig ${ }^{1,2^{*}}$ D, Sandra Ribes ${ }^{1}$, Catharina Diesselberg ${ }^{1}$, Stephanie Bunkowski ${ }^{1}$, Roland $\mathrm{Nau}^{1,3}$ and Sandra Schütze ${ }^{1,4}$
}

\begin{abstract}
In order to elucidate the causes for the increased mortality of aged patients with bacterial central nervous system (CNS) infections, we compared the course of Streptococcus pneumoniae (S. pneumoniae) meningitis in aged and young mice. Aged (21.2 \pm 3.1 months, $n=40)$ and young ( $3.2 \pm 0.9$ months, $n=42) C 57 \mathrm{BL} / 6 \mathrm{~N}$ and B6/SJL mice were infected by intracerebral injection of 50-70 CFU S. pneumoniae serotype 3 and monitored for 15 days. Aged and young mice did not differ concerning mortality (35\% versus 38\%), weight loss, development of clinical symptoms, bacterial concentrations in cerebellum and spleen as well as the number of leukocytes infiltrating the CNS. In contrast to results from our geriatric mouse model of Escherichia coli (E. coli) meningitis, where aged mice showed a higher mortality and an impaired elimination of bacteria, we did not find any differences between aged and young mice after intracerebral infection with S. pneumoniae serotype 3 . This indicates that the increased susceptibility of aged mice to bacterial CNS infections is pathogen-specific: It appears less prominent in infections caused by hardly phagocytable pathogens with thick capsules like S. pneumoniae serotype 3 , where the age-related decline of the phagocytic capacity of microglia and macrophages has a minor influence on the disease course.
\end{abstract}

Keywords: Immunosenescence, Age, Mouse model, Streptococcus pneumoniae, Bacterial meningitis, Survival, CNS

\section{Background}

As a consequence of increasing life expectancy, the population is ageing. It is estimated that in 2050 in all major areas of the world except Africa nearly one quarter or more of the population will be $\geq 60$ years. Globally, the number of persons aged $\geq 80$ years is projected to more than triple by 2050 and to increase more than seven-fold by 2100 [1]. Infectious diseases play an important role in the increasing group of elderly people and are accompanied by a higher mortality and a more severe course of disease $[2,3]$. Bacterial meningitis is an infectious emergency. Elderly patients more often develop severe neurological symptoms like coma, epileptic seizures or focal neurological deficits and show an increased mortality in comparison to younger patients $[4,5]$. In persons aged $\geq 60$ years, the incidence of $S$. pneumoniae meningitis

\footnotetext{
* Correspondence: anja.manig@med.uni-goettingen.de

'Institute of Neuropathology, University Medical Center Göttingen,

Robert-Koch-Str. 40, 37075 Göttingen, Germany

${ }^{2}$ Department of Clinical Neurophysiology, University Medical Center

Göttingen, Robert-Koch-Str. 40, 37075 Göttingen, Germany

Full list of author information is available at the end of the article
}

is approximately 4 times higher and the relative frequency of Listeria monocytogenes meningitis is even 15 times higher compared to persons from 2 to 29 years of age [6]. There is an increasing need to elucidate the causes for the increased incidence and mortality of bacterial CNS infections in the expanding population of the elderly and to identify strategies that can protect the elderly against bacterial CNS infections. In our previously published geriatric mouse model of $E$. coli meningitis, aged mice showed an impaired elimination of bacteria and a reduced systemic cyto-/chemokine response accompanied by a faster development of clinical symptoms, a more pronounced and sustained weight loss and a higher mortality [7]. In vitro, primary murine macrophages and microglial cells showed an age-related decline of their ability to phagocytose $E$. coli [7]. These results suggested, that strategies to increase the phagocytic potential of aged macrophages and microglial cells appear promising for the prevention and therapy of CNS infections in the elderly. Here, we compared the disease course in aged and young mice after intracerebral infection with the most frequent pathogen S. pneumoniae.

(c) The Author(s). 2018 Open Access This article is distributed under the terms of the Creative Commons Attribution 4.0 International License (http://creativecommons.org/licenses/by/4.0/), which permits unrestricted use, distribution, and 


\section{Methods}

$S$. pneumoniae serotype 3 , originally isolated from an adult patient with meningitis (gift from Prof. Dr. M. G. Täuber, Division for Infectious Diseases, University of Bern, Switzerland), was grown on blood agar plates, stored at $-80{ }^{\circ} \mathrm{C}$, and diluted in saline. 40 mice at an age of $21.2 \pm 3.1$ months (aged mice; $19 \mathrm{BL6} / \mathrm{SJL}$ and 21 $\mathrm{C} 57 \mathrm{BL} / 6 \mathrm{~N})$ and 42 mice at an age of $3.2 \pm 0.9$ months (young mice; $25 \mathrm{BL} 6 / \mathrm{SJL}$ and $17 \mathrm{C} 57 \mathrm{BL} / 6 \mathrm{~N}$ ) were anesthetized with $2 \mathrm{mg}$ ketamine and $0.2 \mathrm{mg}$ xylazine and infected by injection of $10 \mu \mathrm{l}$ saline containing 50-70 colony-forming units (CFU) of S. pneumoniae serotype 3 into the superficial right frontal cortex and subarachnoidal space through the right frontolateral skull. The inoculum dose of 50-70 CFU of S. pneumoniae serotype 3 has been identified to cause death in $50 \%$ of young C57BL/6N mice $\left(\mathrm{LD}_{50}\right)$ in previous preliminary experiments. During the acute phase of infection (up to $96 \mathrm{~h}$ after infection) mice were monitored every $12 \mathrm{~h}$ and later on the 7th, 10th and 14th day. Monitoring included weighing and assignment of a clinical score: 0 (no apparent behavioral abnormality), 1 (moderate lethargy), 2 (severe lethargy), 3 (unable to walk), 4 (dead) [8]. When a mouse was no longer able to walk (clinical score 3 ), it was killed for ethical reasons. 15 days after infection, all surviving mice were killed by cervical dislocation. $30 \mathrm{~h}$ after infection, blood was taken from the retrobulbar plexus and bacterial concentrations were determined by quantitative plating on blood agar plates (detection limit $1000 \mathrm{CFU} / \mathrm{ml}$ ). After death, brain and spleen were removed. One half of the cerebellum and one half of the spleen were homogenized in $500 \mu$ l saline, respectively. Bacterial concentrations in cerebellum and spleen were determined by quantitative plating on blood agar plates (detection limit $100 \mathrm{CFU} / \mathrm{ml}$ ). The left hemisphere of the brain was fixed in $4 \%$ formaline, embedded in paraffin, and $2 \mu \mathrm{m}$ coronal brain sections were used for chloracetate esterase (CAE) staining (Naphthol-AS-D-chloracetate esterase Kit, Sigma-Aldrich, Germany). Stained sections were semi-quantitatively scored for the number of neutrophilic granulocytes in one high-power field ( $\times 40$ objective), respectively, in three superficial meningeal regions and the hippocampal fissure for the number of neutrophilic granulocytes using a meningeal inflammation score (no leukocytes [score 0], < 10 leukocytes [score 1], 10-50 leukocytes [score 2], > 50 leukocytes [score 3], for graphical examples see [7]). Statistical analyses and graphical presentation were performed using GraphPad Prism software 5.0 (GraphPad software, San Diego, California, USA). Parametric data were expressed as means \pm standard deviations and compared using the Student's $t$-test. Non-parametric data were expressed as medians and interquartile ranges and compared using the Mann-Whitney $U$-test. For comparison of survival curves the log-rank test was performed. Correlations were analyzed using Spearman's rank correlation coefficient. $P$ values $<0.05$ were considered statistically significant.

\section{Results}

The overall survival after intracerebral infection with $S$. pneumoniae serotype 3 did not differ between young (mortality 38\%) and aged (mortality 35\%) mice (Fig. 1: log-rank test, $P=0.98$ ). Both groups lost weight during the disease progress. Immediately before infection, weight in young and aged mice was $24 \pm 3 \mathrm{~g}$ and $33 \pm 5.8 \mathrm{~g}$ (mean \pm standard deviation), respectively. There was no significant difference in weight loss between young $(0.9 \pm 0.6 \mathrm{~g})$ and aged $(1.2 \pm 0.8 \mathrm{~g})$ mice (difference weight 0 to $24 \mathrm{~h}$ after infection, mean \pm standard deviation, Student's $t$-test, $P=0.077$ ). The time elapsing before symptoms of disease occurred (clinical score 1) did not differ between young and aged mice (median [25./75. percentile]: young 36 [12/48] h versus aged 36 [18/36] h, Mann-Whitney $U$-test, $P=0.79)$. At $30 \mathrm{~h}$ after infection, $30.6 \%$ of the aged and $22 \%$ of the young mice showed bacterial blood concentrations above the detection limit of $1000 \mathrm{CFU} / \mathrm{ml}$ blood as a sign of septicemia, with aged mice reaching up to a maximum of $10^{8} \mathrm{CFU} / \mathrm{ml}$ blood compared to a maximum of $9 \times 10^{4} \mathrm{CFU} / \mathrm{ml}$ blood of the young mice. Mann-Whitney $U$-test showed no significant differences in the concentrations of S. pneumoniae serotype 3 in blood $30 \mathrm{~h}$ after infection between young and aged mice (median [25./75. percentile]: young $<1000$ $[<1000 /<1000] \mathrm{CFU} / \mathrm{ml}$ blood versus aged $<1000[<1000 /$ 8750] CFU/ml blood, $P=0.19)$. By the time of death due to infection, no differences between young and aged mice concerning the bacterial concentrations of S. pneumoniae serotype 3 in spleen (Fig. 2a, median [25./75. percentile]: young $3 \times 10^{5}\left[1 \times 10^{5} / 7 \times 10^{5}\right]$ versus aged $3.5 \times 10^{5}$ $\left[6.5 \times 10^{4} / 8.5 \times 10^{5}\right] \mathrm{CFU} / \mathrm{ml}, \mathrm{Mann}-$ Whitney $U$-test, $P=0.90$ ) and in cerebellum (Fig. 2b, median $[25 . / 75$. percentile]: young $1 \times 10^{8}\left[6 \times 10^{7} / 7 \times 10^{8}\right]$ versus aged

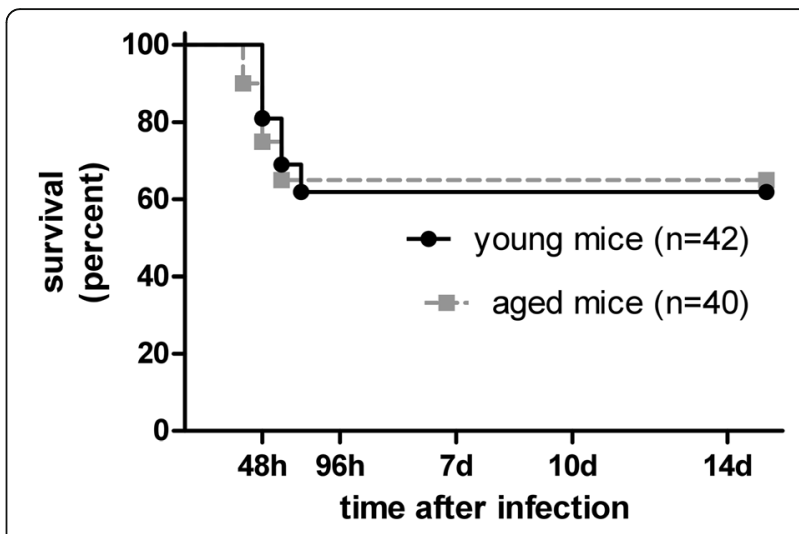

Fig. 1 Kaplan-Meier survival curves of young and aged mice after intracerebral infection with 50-70 CFU of S. pneumoniae serotype 3 

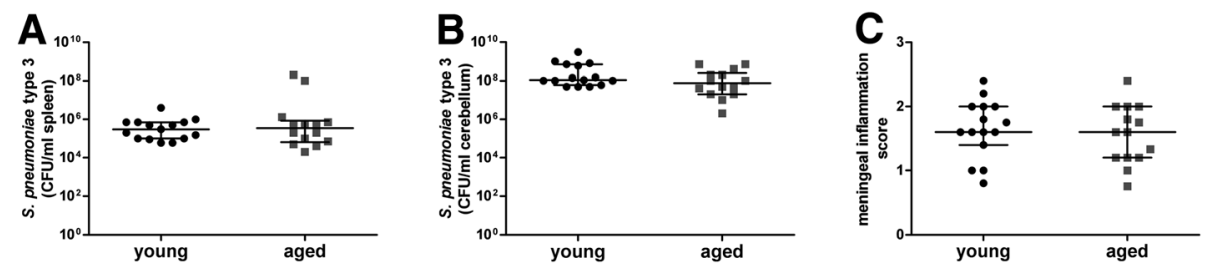

Fig. 2 Bacterial concentrations (CFU/ml) in spleen (a) and cerebellum (b) as well as meningeal inflammation score $(\mathbf{c})$ of young $(n=15)$ and aged $(n=14)$ mice at the time of death caused by intracerebral infection with $\mathbf{S}$. pneumoniae serotype 3 . Symbols represent values of individual mice, and bars indicate medians, 25th and 75th percentiles. Meningeal inflammation score was calculated counting neutrophilic granulocytes in one high-power field ( $\times 40$ objective) on stained sections of three superficial meningeal regions and the hippocampal fissure and classified as follows: no leukocytes [score 0], < 10 leukocytes [score 1], 10-50 leukocytes [score 2], > 50 leukocytes [score 3]

$7.5 \times 10^{7}\left[2 \times 10^{7} / 2.5 \times 10^{8}\right] \quad \mathrm{CFU} / \mathrm{ml}$, Mann-Whitney $U$-test, $P=0.10)$ were detected. 15 days after infection, in all surviving young $(n=26)$ and surviving aged $(n=26)$ mice bacterial concentrations in spleen and cerebellum were below the detection limit of $100 \mathrm{CFU} / \mathrm{ml}$. Comparing the invasion of neutrophilic granulocytes into the subarachnoid space using the meningeal inflammation score by the time of death of acute infection, there was no difference between young and aged mice (Fig. 2c, median [25./75. percentile]: young $1.6[1.4 / 2]$ versus aged $1.6[1.2 / 2]$, Mann-Whitney $U$-test, $P=0.61) .15$ days after infection, 3 of the young and 6 of the aged surviving mice still showed low numbers of leukocytes in the subarachnoid space (maximum meningeal inflammation score: 1 in young and 0.4 in aged mice). However, there was no significant difference in the meningeal inflammation score between surviving young and surviving aged mice 15 days after infection (median [25./75. percentile]: young 0 [0/0] versus aged $0[0 / 0]$, Mann-Whitney $U$-test, $P=0.34)$. In general, there was a significant correlation between the meningeal inflammation score and the bacterial concentration in the cerebellum in young $(r=0.9, P<0.0001)$ as well as in aged $(r=0.87, P<0.0001)$ mice.

\section{Discussion}

The bacterium S. pneumoniae is the most common cause of bacterial meningitis in adults. The incidence of pneumococcal meningitis is four times higher in persons $\geq 60$ years compared to persons aged 2 to 29 years, and mortality is approximately twice as high in patients $\geq 60$ years compared to younger patients (37\% vs. $18 \%)[4,6]$. In a Danish retrospective study of 464 adult patients with invasive pneumococcal disease, serotype 3 accounted for 24 cases (5.3\%). 12 of these 24 patients, i.e. $50 \%$, died. After adjustment for other parameters of disease severity, bacteremic pneumonia, bacteremia with unknown focus, meningitis and otitis media caused by $S$. pneumoniae serotype 3 was associated with an increased mortality (relative risk 2.54 compared to other S. pneumoniae serotypes) [9].
In order to understand the more severe course of the disease of pneumococcal meningitis in elderly patients, we aimed at establishing a murine model which mimics the clinical situation and thus helps to understand the underlying causes. We previously succeeded to do so with another important pathogen of bacterial meningitis in the elderly, E. coli. In our geriatric mouse model of $E$. coli meningitis, aged mice showed a higher mortality, an impaired elimination of bacteria, a faster systemic spread of bacteria and an impaired systemic inflammatory response. In these previous experiments, the numbers of microglia and of infiltrating neutrophilic granulocytes in the subarachnoid space after intracerebral E. coli K1 infection did not differ between young and aged mice, but there was a significant impairment of phagocytosis of $E$. coli $\mathrm{K} 1$ and a decreased release of inflammatory cytokines by aged compared to young microglia and macrophages in vitro [7]. In contrast to these previous results, we did not find any differences in the course of bacterial meningitis caused by S. pneumoniae serotype 3 between young and aged mice. Although in our mouse models the intracerebrally injected dose of E. coli $\mathrm{K} 1$ ( $\left.10^{5} \mathrm{CFU}\right)$ was much higher than that of $S$. pneumoniae serotype 3 (50-70 CFU), mortality, time until death as well as meningeal inflammation scores, and bacterial concentrations in cerebellum and spleen were similar in young mice in both models [7]. These results underline the higher virulence of S. pneumoniae serotype 3 compared to E. coli $\mathrm{K} 1$.

The most important determinant of the virulence of $S$. pneumoniae is its polysaccharide capsule [10]. Possession of a capsule is essential for causing meningitis [11]. Serotype 6B S. pneumoniae strains, which maintained a thick capsule in the cerebrospinal fluid, caused a more severe disease than serotype $7 \mathrm{~F}$ in the same genetic background, which had a much thinner capsule [11]. S. pneumoniae serotype 3 has a thicker capsule compared to most other S. pneumoniae strains [12, 13] which protects against phagocytosis and might account for its high virulence [14]. In neutrophils, increase in capsule size of $S$. pneumoniae is associated with a decreased rate of phagocytosis [15]. The S. pneumoniae serotype 3 strain 
HB565 was resistant to phagocytosis by cells of the microglial BV2-cell line [16]. The S. pneumoniae serotype 3 used in the present experiments (strain A; [17]) produced very large, mucoid colonies on blood-agar plates, and capsular expression was stable during infection in experimental animals. S. pneumoniae serotype 2 D39, which has a thinner capsule compared to S. pneumoniae serotype 3 [13] was phagocytosed by primary murine microglial cells of young mice only in small numbers [18], whereas phagocytosis of the unencapsulated S. pneumoniae strain R6 and also E. coli $\mathrm{K} 1$ was considerably higher $[18,19]$. Microglia as well as perivascular and meningeal macrophages, the immune cells representing the first line of defense of the CNS, undergo age-related changes concerning their phagocytic ability [7, 20]. Aged microglial cells and macrophages show an impaired ability to phagocytose $E$. coli $\mathrm{K} 1$ going along with an impaired elimination of bacteria and an increased mortality in aged mice after intracerebral infection with E. coli K1 [7]. This age-related decline of phagocytosis of pathogens seems to have less impact on the outcome of an infection caused by a hardly phagocytable bacterium with a thick polysaccharide capsule such as $S$. pneumoniae serotype 3. In accordance with our findings, Esposito et al. showed, that a deposition of viable S. pneumoniae serotype 3 in the lower respiratory tract resulted in equal mortality of young and aged C57BL/6 mice [21]. These observations suggest that in the presence of a thick capsule with a high content of capsular polysaccharide neither young nor old phagocytes can control the infection, once pneumococci have reached physiologically sterile body sites, and correspond to the high mortality of invasive $S$. pneumoniae infections caused by serotype 3 strains [9].

Conversely there may be a difference between the resistance to S. pneumoniae infection of old and young animals, when the pneumococcal capsule is thinner and contains smaller amounts of polysaccharide. Intratracheal infection with $S$. pneumoniae serotype 4 showed that aged Balb/cBy mice had a higher mortality and higher bacterial concentrations compared to young Balb/cBy mice [22]. Furthermore, pneumococcal colonization was prolonged and clearance of pneumococci was delayed in the higher respiratory tract in aged compared to young C57BL/6 mice after nasal instillation of S. pneumoniae serotype 6B [23].

In summary, when a highly virulent $S$. pneumoniae type 3 strain was used, no difference was found in the course of meningitis in old and young mice after intracerebral inoculation. Data from other models of infection generated with less virulent serotypes of S. pneumoniae suggest that these less aggressive serotypes may be more suitable to study differences in the age-related susceptibility towards $S$. pneumoniae infections.

\section{Conclusions}

In contrast to results from our geriatric mouse model of E. coli meningitis, where we found a higher mortality and an impaired elimination of bacteria in aged mice compared to young mice, we did not find any significant differences between aged and young mice concerning the disease course after intracerebral infection with the pathogen S. pneumoniae serotype 3. We conclude that the age-related decline of the phagocytic capacity of microglia and macrophages has only a minor impact on the course of CNS infections caused by pathogens with thick capsules such as S. pneumoniae serotype 3. A larger panel of $S$. pneumoniae serotypes should be studied in vivo and in vitro in order to better elucidate age-related susceptibility to this life-threatening pathogen.

\section{Abbreviations}

CAE: Chloracetate esterase; CFU: Colony forming units; CNS: Central nervous system; E. coli: Escherichia coli; S. pneumoniae: Streptococcus pneumoniae

\section{Funding}

This work was supported by a grant of the Robert Bosch Foundation, Stuttgart, Germany - Forschungskolleg Geriatrie (to SS).

\section{Availability of data and materials}

The datasets used and analysed during the current study are available from the corresponding author on reasonable request.

\section{Author's contribution}

AM and SS planned and performed the experiments and wrote the manuscript. SR contributed to the preparation of the bacteria and the evaluation of the histological examination. CD helped with the performing of the infections. SB performed the histological stainings. RN contributed to the planning and interpretation of the data. All authors read and approved the final manuscript.

\section{Ethics approval}

Animal experiments were approved by the Animal Care Committee of the University Hospital of Göttingen, Germany, and by the Niedersächsisches Landesamt für Verbraucherschutz und Lebensmittelsicherheit (LAVES), Braunschweig, Lower Saxony, Germany.

\section{Consent for publication}

Not applicable.

Competing interests

The authors declare that they have no competing interests.

\section{Publisher's Note}

Springer Nature remains neutral with regard to jurisdictional claims in published maps and institutional affiliations.

\section{Author details}

${ }^{1}$ Institute of Neuropathology, University Medical Center Göttingen, Robert-Koch-Str. 40, 37075 Göttingen, Germany. ²Department of Clinical Neurophysiology, University Medical Center Göttingen, Robert-Koch-Str. 40, 37075 Göttingen, Germany. ${ }^{3}$ Department of Geriatrics, Evangelisches Krankenhaus Göttingen-Weende, An der Lutter 24, 37075 Göttingen, Germany. ${ }^{4}$ Department of Geriatrics, AGAPLESION Frankfurter Diakonie Kliniken, Wilhelm-Epstein-Str. 4, 60431 Frankfurt, Germany. 
Received: 15 May 2018 Accepted: 29 August 2018

Published online: 07 September 2018

\section{References}

1. United Nations, Department of Economic and Social Affairs, Population Division. The World Population Prospects: 2015 Revision, key findings and advance tables. New York. Working paper no. ESA/P/WP 2015; 241.

2. Gavazzi G, Krause K-H. Ageing and infection. Lancet Infect Dis. 2002;2:65966.

3. Yoshikawa TT, Norman DC. Geriatric infectious diseases: current concepts on diagnosis and management. J Am Geriatr Soc. 2017;65:631-41.

4. Cabellos C, Verdaguer R, Olmo M, Fernández-Sabé N, Cisnal M, Ariza J, et al. Community-acquired bacterial meningitis in elderly patients: experience over 30 years. Medicine (Baltimore). 2009;88:115-9.

5. Weisfelt M, van de Beek D, Spanjaard L, Reitsma JB, de Gans J. Community-acquired bacterial meningitis in older people. J Am Geriatr Soc. 2006;54:1500-7.

6. Schuchat A, Robinson K, Wenger JD, Harrison LH, Farley M, Reingold AL, et al. Bacterial meningitis in the United States in 1995. Active Surveillance Team N Engl J Med. 1997:337:970-6.

7. Schütze S, Ribes S, Kaufmann A, Manig A, Scheffel J, Redlich S, et al Higher mortality and impaired elimination of bacteria in aged mice after intracerebral infection with E. Coli are associated with an agerelated decline of microglia and macrophage functions. Oncotarget. 2014;5:12573-92.

8. Gerber J, Raivich G, Wellmer A, Noeske C, Kunst T, Werner A, et al. A mouse model of Streptococcus pneumoniae meningitis mimicking several features of human disease. Acta Neuropathol (Berl). 2001;101:499-508.

9. Martens P, Worm SW, Lundgren B, Konradsen HB, Benfield T. Serotype specific mortality from invasive Streptococcus pneumoniae disease revisited. BMC Infect Dis. 2004:4:21.

10. Geno KA, Gilbert GL, Song JY, Skovsted IC, Klugman KP, Jones C, et al. Pneumococcal capsules and their types: past, present, and future. Clin Microbiol Rev. 2015;28:871-99.

11. Hathaway LJ, Grandgirard D, Valente LG, Täuber MG, Leib SL. Streptococcus pneumoniae capsule determines disease severity in experimental pneumococcal meningitis. Open Biol. 2016;6 https://doi. org/10.1098/rsob.150269.

12. MacLEOD CM, Kraus MR. Relation of virulence of pneumococcal strains for mice to the quantity of capsular polysaccharide formed in vitro. J Exp Med. 1950;92:1-9.

13. Hyams C, Camberlein E, Cohen JM, Bax K, Brown JS. The Streptococcus pneumoniae capsule inhibits complement activity and neutrophil phagocytosis by multiple mechanisms. Infect Immun. 2010;78:704-15.

14. Weinberger DM, Harboe ZB, Sanders EAM, Ndiritu M, Klugman KP Rückinger $\mathrm{S}$, et al. Association of serotype with risk of death due to pneumococcal pneumonia: a meta-analysis. Clin Infect Dis Off Publ Infect Dis Soc Am. 2010;51:692-9.

15. Weinberger DM, Trzciński K, Lu Y-J, Bogaert D, Brandes A, Galagan J, et al. Pneumococcal capsular polysaccharide structure predicts serotype prevalence. PLoS Pathog. 2009;5:e1000476.

16. Peppoloni S, Ricci S, Orsi CF, Colombari B, De Santi MM, Messinò M, et al. The encapsulated strain TIGR4 of Streptococcus pneumoniae is phagocytosed but is resistant to intracellular killing by mouse microglia. Microbes Infect. 2010;12:990-1001.

17. Täuber MG, Burroughs M, Niemöller UM, Kuster H, Borschberg U, Tuomanen E. Differences of pathophysiology in experimental meningitis caused by three strains of Streptococcus pneumoniae. J Infect Dis. 1991;163:806-11.

18. Ribes S, Ebert S, Regen T, Agarwal A, Tauber SC, Czesnik D, et al. Toll-like receptor stimulation enhances phagocytosis and intracellular killing of nonencapsulated and encapsulated Streptococcus pneumoniae by murine microglia. Infect Immun. 2010;78:865-71.

19. Ribes S, Ebert S, Czesnik D, Regen T, Zeug A, Bukowski S, et al. Toll-like receptor prestimulation increases phagocytosis of Escherichia coli DH5alpha and Escherichia coli K1 strains by murine microglial cells. Infect Immun. 2009;77:557-64.

20. Floden AM, Combs CK. Microglia demonstrate age-dependent interaction with amyloid- $\beta$ fibrils. J Alzheimers Dis JAD. 2011;25:279-93.

21. Esposito AL, Poirier WJ, Clark CA. In vitro assessment of chemotaxis by peripheral blood neutrophils from adult and senescent C57BL/6 mice: correlation with in vivo responses to pulmonary infection with type 3 Streptococcus pneumoniae. Gerontology. 1990;36:2-11.

22. Boyd AR, Shivshankar P, Jiang S, Berton MT, Orihuela CJ. Age-related defects in TLR2 signaling diminish the cytokine response by alveolar macrophages during murine pneumococcal pneumonia. Exp Gerontol. 2012;47:507-18.

23. Krone $\mathrm{CL}$, Trzciński K, Zborowski T, Sanders EAM, Bogaert D. Impaired innate mucosal immunity in aged mice permits prolonged Streptococcus pneumoniae colonization. Infect Immun. 2013;81:4615-25.
Ready to submit your research? Choose BMC and benefit from:

- fast, convenient online submission

- thorough peer review by experienced researchers in your field

- rapid publication on acceptance

- support for research data, including large and complex data types

- gold Open Access which fosters wider collaboration and increased citations

- maximum visibility for your research: over $100 \mathrm{M}$ website views per year

At $\mathrm{BMC}$, research is always in progress.

Learn more biomedcentral.com/submissions 